\title{
The Relationship between Assertiveness and Job satisfaction among Nursing Personnel at Benha University Hospital
}

\author{
* Sabrein Moustafa Abd Elsalam Hamouda, **Nermin Mohamed Eid, * Hoda Abd- Alla \\ Saleh. \\ *Nursing Administration, Faculty of Nursing, Benha University, **Nursing Administration, Faculty \\ of Nursing, Elmonofia Univeristy.
}

\begin{abstract}
Nursing staff are the core stone in the healthcare organizations, Assertiveness enhances communication in work place and it increase the job satisfaction among nurses. Aim:-The study aimed to assess the relationship between assertiveness and job satisfaction among nursing personnel. Design:- Descriptive correlational design was used in this study Setting:- This study was conducted at Medical and Surgical departments Benha University Hospital. Subjects:Included in this study were composed of (225) of nursing personnel working at the previously mentioned departments. Tools: - Two tools were used for data collection assertive behavior questionnaire and job satisfaction questionnaire Results:- The findings of the present study revealed that the majority of the nursing personnel had highly assertive and they were satisfied with their job. Conclusion: - The findings concluded that there was a positive correlation between nurses' assertiveness and their job satisfaction and this relation was statistical significance difference. Recommendations:- Periodical assessment for nursing staff work environment to reduce prediction and passivity, maintaining continuous staff development activities for nurses to improve their attitude, knowledge and skills in order to improve their assertiveness level. Encouraging excellent nurses by recognition and incentives are very important.
\end{abstract}

Key words: Nursing assertiveness, job satisfaction and nursing personnel.

Introduction

Nursing is an interpersonal process involving human beings, which is why ability to forge human relations bears considerable significance in the field of nursing. In particular, without effective communication, a therapeutic relationship between nurse and patient cannot be formulated nor can nursing intervention be performed (King, 2007).

Assertive behavior and good communication are inextricably linked, Assertive behavior requires effective communication and lack of assertiveness result in the diminished effectiveness of communication (McCabe and Timmins F, 2010).
Assertiveness is a form of communication in which needs or wishes are started clearly with respect for oneself and the other person in the interaction (Seyedfatemi, Khoshnavaye. And Behbahani, 2009). Assertiveness helps the nurses in stress management, especially if they tend to take on too many responsibilities, because they have a hard time saying no. Beying assertive is a core communication skill, based on mutual respect, it's an effective and diplomatic communication style can help the nurses to control stress, anger and improve coping skills (Elder, Evans and Nizette, 2013). 
Assertiveness is considered to be healthy and desirable behavior for all people who interact in situation in so far as it militates against personal powerlessness and can result in personal empowerment and ultimately benefit the group, or workplace as a whole. Although some nursing studies have found assertive behavior in nursing practitioners to be an invaluable component of successful professional practice (Kilkus, 2008).

Assertive behavior develops respect towards self and other nurses, promotes selfdisclosure, self-control, increase confidence, satisfactory communication (McCabe and Timmins F, 2010) and positive appreciation of self-worth. It is the most effective way of solving interpersonal problems and conflicts. Assertive nurses become happier, less manipulative, feel better about them and reach their goals more easily. Acting assertively can increase the nurses' chances for honest relationships, give a sense of control in everyday situations, achieving what they want, provide reassurance to the nurses as, improve decision-making ability, and increase work effectiveness and productivity (Hodgetts, 2011).

For any organization, job satisfaction of its workers means a healthier work force that is productive, retained and motivated. There will be significant reduction in complaints, grievances, absenteeism, turnover, termination; and significant improvement in punctuality and morale (Yaffee and Kark, 2011) Job satisfaction reflects the extent to which an individual likes the job. And the organizations with satisfied employees are more productive than those with unsatisfied employees (Hellriegel and Slocum, 2007).

Nurses who were not satisfied at work were also found to distance themselves from their patients and their nursing chores (Shinde and Durgawale, 2014).so job satisfaction is a critical issue in health care that affects all those responsible for maintaining and growing a reliable and competent health care workforce. Increasing overall staff job satisfaction can improve retention and patient outcomes (Hayes et al., 2012) and it is can positively affect the overall work of the organization, whereas job dissatisfaction can negatively impact the work of the organization (McGlynn, et al, 2012).

A positive correlation exists between assertiveness role clarity, job and career satisfaction (Karakas, 2015). Assertiveness is viewed by Hargie (2011) as a valued behavior within nursing, resulting in positive outcomes such as the enhancement of leadership skills, an increase in job satisfaction and avoidance of compromising patient care alleviation of job stress, the heightening of nurses, effectiveness in bringing about change and a greater insight into the factors that influence the responding style is necessary. McCabe $\mathbf{C}$ and Timmins F, (2010) pointed that assertive nurses can handle confrontation more easily and satisfactory, feeling ease, having greater selfconfidence, being tactful, away that maintains the effectiveness of the relationship, resisting other`s attempts to manipulate themselves.

\section{Significant of the study:}

Actually nursing moves toward expanded roles and more responsibilities in patient care, so new approaches must be developed. The nurses need to be independent, decisive, assertive individuals in order to achieve selfconfidence in their knowledge and abilities. The more nurses are satisfied with their action and more energy they will have to devote to their patient care. Therefore, this study was carried out to investigate the relationship between assertiveness and job satisfaction among nursing personnel at Benha University Hospital. 
Aim of the study:

The study aimed to assess the relationship between assertiveness and job satisfaction among nursing personnel.

\section{Research Questions}

1) Do nurses have assertive behavior?

2) What are the job satisfaction levels among nursing personnel?

3) Is there a relation between nursing personnel assertive behavior and their job satisfaction?

Subjects \& methods:

Design: Descriptive - correlational research design was utilized to conduct this study.

Setting: The study was conducted at Medical and Surgical departments at Benha University Hospital: It includes 27 units, Medical departments 14 unit and Surgical departments 13 units

Subjects The subject included in this study consisted of the nursing personnel who were working at Medical and Surgical departments.

They were selected by representative sample of (225) nurses from the total number (512) nurses. The sample size was calculated according to the following formula:

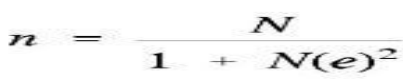

Where ' $n$ ' is sample size.

' $\mathrm{N}$ ' is Number of one year (2014) at Governmental hospitals $=512$

' $\mathrm{e}$ ' is Coefficient factor $=0.05$

\section{Tools of data collection:}

To collect data for this study the following tools were used.

First tool:-Assertive Behavior questionnaire: It was used to assess assertiveness among nursing personnel; the questionnaire was adapted from Gouda, (2009) and essential modifications were done by the researcher.

Part I: concerned with personal data of nursing personnel such as (age, gender, marital status, educational qualification, and years of experience).

Part II: Included 68 statements grouped under six domains of assertiveness as the following:- Verbal and nonverbal(11) items, Active orientation(7) items, Work habit(7) items, Control of anxiety(29) items, Relating to coworkers(11) items, Negotiating the system(3) items.

Each item of the assertiveness Likert Scale was scored as (0) for never response, (1) for rarely,(2) for sometimes,(3) for usually and (4) for often.

Total assertiveness score of each assertiveness dimension was determined as the following according to the point of view of the statistical person:-

$$
\begin{aligned}
& 0=\text { un assertive } \\
& <60 \%=\text { partially assertive } \\
& \geq 60 \%=\text { highly assertive }
\end{aligned}
$$

The second tool: Job satisfaction questionnaire. It was adopted from Ahmed, (2006) to assess job satisfaction among nursing personnel at Benha University Hospital. It consisted of 79 items that measures eight domain of job satisfaction, which are: Hospital policy(5) items, 
Relations at work(17) items, Work environment(15) items, Work system(10) items, Salaries and Incentives(5) items, Achievement(18) items, psychiatric state(4) items, Safety at work(5) items,

\section{Scoring system:}

Scoring system of job satisfaction questionnaire; each item was scored as $(0)$ for no, (1) for sometimes and, (2) for yes.

Total satisfaction score of each satisfaction dimension was determined as the following according to the point of view of the statistical person:-

$$
\begin{aligned}
& \text { Satisfactory-------------------- } \geq 60 \% \\
& \text { Unsatisfactory ----------------<60\% }
\end{aligned}
$$

Reliability of instrument Test-retest reliability and internal consistency for the assertive behavior tool were $(\mathrm{r}=0.93$ and $\alpha=0.93 \quad$ respectively, $(\mathrm{p}<0.0005)$. The Cronbach's alpha coefficient for each dimension were verbal and nonverbal $(\alpha=0.82)$, active orientation $(\alpha=0.87)$, work habit $(\alpha=0.91)$, control of anxiety $(\alpha=0.84)$, relating to coworkers $(\alpha=0.86)$, negotiating the esteem emotional $(\alpha=0.94)$.

Test-retest reliability and internal consistency for Job satisfaction tool were (r $=0.96$ and $\alpha=0.92$ respectively. $(p<0.0005)$. The Cronbach's alpha coefficient for each dimension were Hospital Policy $(\alpha=0.85)$, Relations at work $(\alpha=0.90)$, Work environment $(\alpha=0.87)$, Work system $(\alpha=0.91)$, Salaries and Incentives $(\alpha=0.92)$, Achievement $(\alpha=0.86)$ psychiatric state $(\alpha=0.89)$, and Safety at work $(\alpha=0.90)$.

3- Pilot study: Pilot study was conducted to assess tool clarity and applicability. It had also served in estimating the time needed for filling the form. The study was tested on $10 \%$ of total subjects (23). There was no change accrued of the pilot study so this sample was included in the study.

4-Procedure: Each nurse was interviewed after explaining the purpose of the study and getting agreement of staff nurses to participate in the study.

- Data has been collected from staff nurses in above mentioned study at Benha University Hospital. Collection of data took four months at Benha University Hospital from beginning of July / 2015 to the end of October/2015. the researcher applied interview for study sample for three days peer a week. The time needed to complete questionnaire sheet take from $(15: 20)$ minutes.

\section{Ethical consideration:}

The study was conducted with careful attention to ethical standards of research and rights of the participants:

\section{Informed consent}

The respondent rights was protected by ensuring voluntary participation, so the informed consent obtained by explaining purpose, nature time of conducting the study, potential benefits of the study, how data will be collected, any invasive procedure, expected outcomes and the respondent rights to withdrawing from the research study at any time in case of violation of his rights.

\section{- Anonymity \& confidentiality}

The respondent was assured that the data was treated as strictly confidential; furthermore, the respondent anonymity was maintained as they weren't require mentioning their names.

\section{Scientific honesty}

To ensure scientific honesty, the researcher uses bracketing \& intuiting to avoid bias 


\section{Statistical design}

Data entry and statistical analysis were performed using personal computer software, the statistical package for social sciences (SPSS), version 24. Suitable descriptive statistics were used such as; frequency, percentage, mean and standard deviation. Chi-square test was used to detect the relation between the variables. In addition, correlation coefficient (r) test was used to estimate the closeness association between variables. The $\mathrm{p}$-value is the degree of significant and using the correlation ( $r$ ) test. The p-value is the probability that an observed difference is due to chance and not a true difference. A significant level value was considered when $\mathrm{p}$-value $\leq 0.05$ and a highly significant level value was considered when $\mathrm{p}$-value $\leq 0.001$, while $\mathrm{p}$-value $>0.05$ indicates non-significant results. 
Result

Table (1). Reveals distribution of nursing personnel according to their personal characteristics, it indicates that $42.7 \%$ of them had age group between $25-35$ years old with mean of $28.39 \pm 9.53$, all of them were female, $64.9 \%$ of them had a secondary nursing education, $84.0 \%$ of them were married, $78.2 \%$ of them were resident at urban settings and $78.2 \%$ of them were not attended any training courses

Table (1): Distribution of nursing personnel According to their personal characteristics (No 225)

\begin{tabular}{|c|c|c|}
\hline Personnel characteristic & Frequency & $\%$ \\
\hline & 36 & 16.0 \\
\hline $20-$ & 96 & 42.7 \\
\hline $25-$ & 79 & 35.1 \\
\hline $35-$ & 9 & 4.0 \\
\hline $45-$ & 5 & 2.2 \\
\hline $55-$ & & \\
\hline Mean \pm SD & \multicolumn{2}{|c|}{$28.39 \pm 9.53$} \\
\hline \multicolumn{3}{|l|}{ Sex } \\
\hline Female & 225 & 100.0 \\
\hline Male & 0 & .0 \\
\hline \multicolumn{3}{|l|}{ Educational qualification } \\
\hline Bachelor degree in nursing & 8 & 3.6 \\
\hline Technical nursing institute & 50 & 22.2 \\
\hline Secondary nursing education diploma & 146 & 64.9 \\
\hline Secondary nursing education + specialty & 21 & 9.3 \\
\hline \multicolumn{3}{|l|}{ Years of experience } \\
\hline $1-$ & 26 & 11.6 \\
\hline 5- & 86 & 38.2 \\
\hline $15-$ & 85 & 37.8 \\
\hline $25-$ & 19 & 8.4 \\
\hline $35-$ & 9 & 4.0 \\
\hline Mean \pm SD & \multicolumn{2}{|c|}{$17.56 \pm 7.08$} \\
\hline \multicolumn{3}{|l|}{ Working setting } \\
\hline Medical & 128 & 56.9 \\
\hline Surgical & 97 & 43.1 \\
\hline \multicolumn{3}{|l|}{ Marital status } \\
\hline Married & 189 & 84.0 \\
\hline Single & 36 & 16.0 \\
\hline \multicolumn{3}{|l|}{ Residence } \\
\hline Rural & 93 & 41.3 \\
\hline Urban & 132 & 58.7 \\
\hline \multicolumn{3}{|l|}{ Training courses } \\
\hline Yes & 49 & 21.8 \\
\hline No & 176 & 78.2 \\
\hline \multicolumn{3}{|l|}{ Number of training courses } \\
\hline 1 & 10 & 20.4 \\
\hline 2 & 25 & 51.0 \\
\hline 3 & 9 & 18.4 \\
\hline 4 & 5 & 10.2 \\
\hline
\end{tabular}


Figure (1): Percentage distribution of nursing personnel according to their total assertiveness scores this figure showed that the majority of the studied nurses had a high level of assertiveness mean scores $(80.9 \%)$.

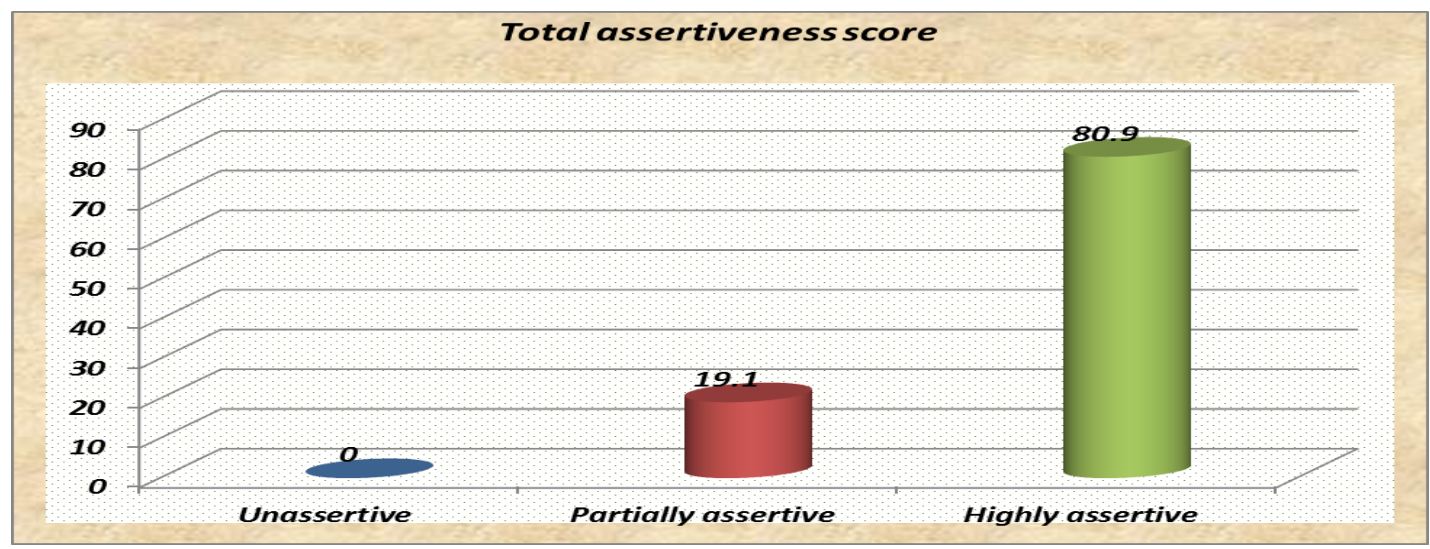

Figure (1): Percentage distribution of nursing personnel according to their total

\section{Assertiveness scores.}

Figure(2): shows percentage distribution of nursing personnel job satisfaction related dimensions shows the highest percentage was related to work relation $(80.4 \%)$ while the least percentage was related to salaries and incentive $(28.4 \%)$.

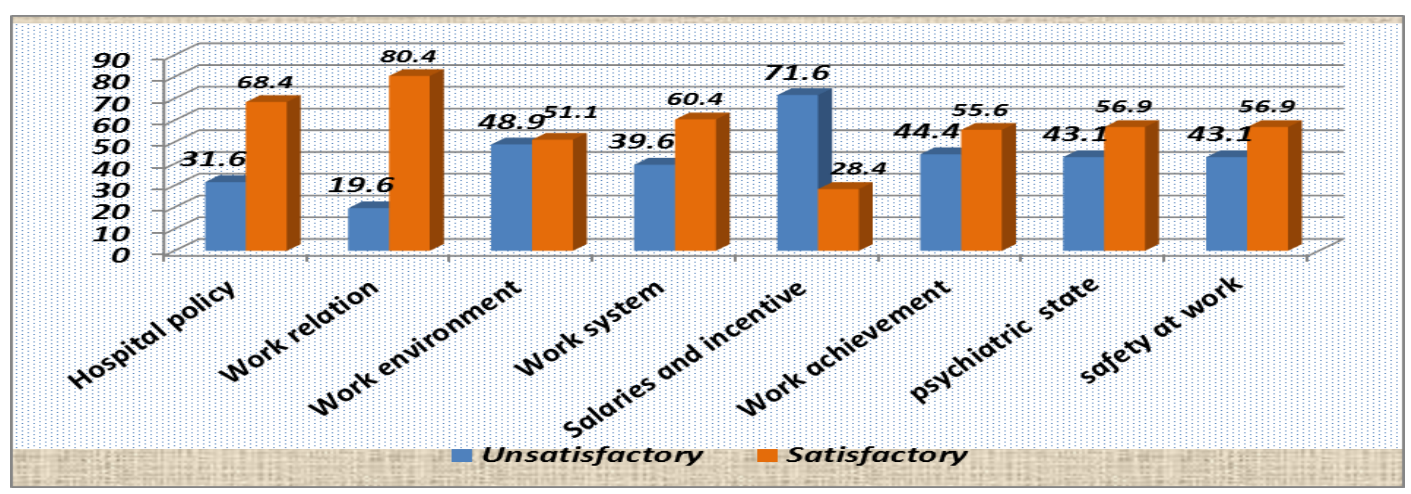

Figure (2): Percentage distribution of nursing personnel according to job satisfaction related dimensions. 
Figure (3): shows Percentage distribution of nursing personnel total job satisfaction scores showed that the more than half of the nursing personnel had a high level of job satisfaction mean scores $(58.2 \%)$.

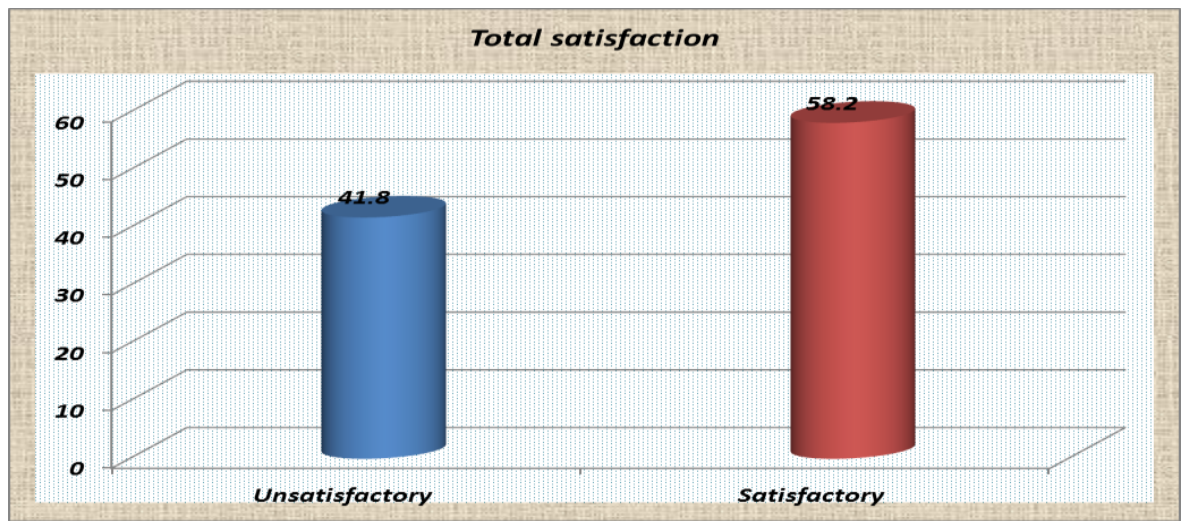

Figure (3): Percentage distribution of nursing personnel according to their total job satisfaction scores

Table (2): correlation between nursing personnel total assertiveness scores and job satisfaction scores shows a positive correlation between assertiveness of nurses and their job satisfaction, finally, these correlations were statistically significant.

Table (2): Correlation between nursing personnel total assertiveness scores and job satisfaction scores

\begin{tabular}{|c|c|c|}
\hline \multirow{2}{*}{ Variable } & \multicolumn{2}{|c|}{ Assertiveness } \\
\cline { 2 - 3 } & $\mathbf{r}$ & P value \\
\hline Satisfaction & $.462(* *)$ & .000 \\
\hline
\end{tabular}

** Correlation is significant at the 0.01 level (2-tailed).

\section{Discussion}

As regarding to distribution of the studied sample according to their socio demographic characteristics. The result indicated that the total study samples were (225) staff nurse. The highest percentage of them $(42.7 \%)$ their age ranged between $25-35$ years old, as regarding to educational qualification the highest percentage $(64.9 \%)$ have a secondary nursing education. As regarding to years of experience the highest percentage $(38.2 \%)$ ranged between $5-10$ years of experience and in relation to marital status the majority of study sample $(84.0 \%)$ was married. While as regarding of training program more than half of study sample $(78.2 \%)$ not have any training programs about assertiveness.

According to the study finding, there was non statistical significant difference between assertiveness and the educational qualification of the studied nurses, this finding was incongruent with several research studies which concluded that there 
was a positive association between stronger assertiveness and higher educational levels (Essa, 2009) in Egypt at Zagazig University Hospital. According to the study finding, there was non statistical significant difference between assertiveness and age or the years of experiences of the studied nurses this result was congruent with Unal (2012) examined assertiveness in 79 nursing students and found that age and sex were not related with assertiveness in Ankara at Gazi Universits Facults of Health scienes Besevler. In contradictory with the previous findings, Kilkus (2008) in Minnesta State Board of Nursing at Winona state University who had concluded that, the oldest group of nurses was significantly less assertive than any of the younger groups of nurses also the study finding. In contradictory with Küçük, Buzlu, and Can, (2008) in their study the assertiveness of the students stated that as the age increased so did their assertiveness in Istanbul at Istanbul Universites.

The finding of the present study had indicated that there was a highly statistical significant difference between attending training courses about assertiveness and the level of assertiveness of studied nurse from the point of view of the researcher this may be lead to increased personal maturity, increased knowledge or responsibility and their interpersonal skills and their experiences gained by developing their learning which in turn increased ability to negotiating a workable situation, managing conflict, take appropriate decision, solve problems and increase their ability to maintain their assertiveness skills in interactions with others.

The finding was congruent with Arslan, Akça, and Nand Baser (2013)in Tukeya at Bozok University Health School who founded that two third of the subject of his study were described as assertive, also the previous finding was consistent with Kilkus (2008) who found that the majority of staff nurses were assertive in Minnesta State Board of Nursing at Winona state University.

For nurse's job satisfaction, the studied nurse were satisfied with hospital policy, work relation, work environment, work system, work achievement, safety at work and psychiatric state but they were not satisfied about salaries, and incentives, and this result showed that more than half of staff nurses were satisfied so this findings answer the second research question from the point of view of the researcher this means that the management of the Benha Hospital University attempted to be more focused on the factors which improve and achieve better satisfaction among nurses this finding agreed with study in Albania (Gabrani Adriatik, 2014) concluded that nurses at public hospitals in Albania experienced high level of overall job satisfaction.

Concerning the relationship between assertiveness and job satisfaction among nursing personnel, according to the present study, there was a positive correlation between assertiveness and job satisfaction, these findings answered the third research question of this study that nurses who were more assertive would be more satisfied with their job.

This was supported by Mayo Clinic Staff, (2012) as stated that behaving assertively can help the nurse to: gain selfconfidence and self-esteem; understand and recognize your feelings; earn respect from others; improve communication; create winwin situations; improve decision-making skills; create honest relationships; and gain more job satisfaction. And this also agreed with Kamal, (2009), who reported that there is appositive correlation between assertive nurses behavior and their job satisfaction in Egypt at Zagazig University Hospital. 
Conclusion

In the light of the present study it can be concluded that majority of nurses at Surgical and Medical departments at Benha University Hospitals were highly assertive, and they were satisfied with their job.

There was a positive correlation between nursing personnel assertiveness and their job satisfaction and this relation was statistical significance difference.

\section{Recommendations}

In the lights of the findings obtained from the present study these points are recommended:

1.Periodical assessment for nursing staff work environment to reduce prediction and passivity

2.Encouraging excellent nurses by recognition, emotional and monitory incentives are very important.

3.Nurse Managers match nurses needs and interest with work need for the satisfaction of both.

4.Periodic meeting of staff nurses with the managers of nursing must be maintained to discuss and solve work problems and set action plans to enhance nurse job satisfaction.

5.Assertive training programme are needed for the nursing staff.

6.There should be a continuing educational department to train staff nurses and provide facilities, media, budget, and resources needed, based on nurses skills, this is required to upgrade their efficiency and improve their skills.
7.Further research is required to investigate the factors that may improve the level of assertiveness and job satisfaction among nurses staff personnel.

\section{References:}

Ahmed, E. (2006): Work empowerment and job satisfaction among nurses. Zagazig Nursing Journal: 2(3) Pp, 68-69.

Arslan, E., Akça. K., and Nand Baser. (2013):Levels of Assertiveness and Peer Pressure of Nursing Students International Journal of Caring Sciences January-April 6 (1),pp 78-86.

Elder, R., Evans, K., and Nizette, D. (2013): Psychiatric and Mental Health Nursing (3rd ed.). Elsevier pbublishers, 326.

Essa, A. (2009): Assertiveness among Nursing Personnel at Zagazig University Hospital. Master Thesis 5860-63-65.

Gabrani Adriatik, H. (2014): Perceived organizational commitment and job satisfaction among nurses in Albanian public hospitals: A cross-sectional study. International Journal of Healthcare Management, 7, ( 1), pp1 9.

Hayes, L., O’Brien-Pallas, L., Duffield, C., Shamian, J., Buchan, J., Hughes, F., and North, N. (2012): Nurse turnover: A literature review - An update. International Journal of Nursing Studies, (49), pp 887-905.

Hellriegel, D., and Slocum, J. (2007): Organizational Behavior. (11th Edition) p.55 .Thomson South-Western. USA: South Western Cengage Learning

Hodgetts, S. (2011): Being assertive benefits everyone. Nurse Times. 107(47), pp 41. 
Kamal, A. (2009): Assertiveness and job satisfaction among nursing personal at Zagazig University Hospital Unpublished M.S.c.N. Thesis in nursing Administration, Zagazig University.

Karakas, S. (2015): The Effect of Assertiveness Training on the Mobbing That Nurses Experience. Workplace Health Saf 63 (10):pp 446-451

Kilkus, S. (2008): Assertiveness among professional nurses. Journal of advance nursing, 18(8) pp1324-1330.

King, I. (2007): King's conceptual system, theory of goal attainment, and transaction process in the 21 st century. Nursing Science Quarterly, 20 (2),pp109-111. Retrieved from http:// search.ebscohost.com.libproxy.unh.edu/ login.aspx ?direct $=$ true $\& d b=$ rzh $\& A N=2$ 009606327\&site=ehost-live

Küçük, L., Buzlu, S., and Can, G. (2008): Level of assertiveness of nursing students, Journal of Nursing 16 (62),pp 90-96.

Mayo Clinic Staff. (2012): Being assertive: Reduce stress, communicate better. http://wwwMayoClinic.com

McCabe, C., and Timmins, F. (2010): The importance of assertive behaviour by nurses in becoming autonomous practitioners, Faculty of Nursing, 25th Annual Nursing and Research Conference, Royal College of Surgeons in Ireland, Stephen's Green, Dublin, 2325th February.
McGlynn, K., Griffin, M., Donahue, M., and Fitzpatrick, J. (2012): Registered nurse job satisfaction and satisfaction with the professional practice model. Journal of Nursing Management, 20(2), pp 260265.

Sanders, R. (2007): Assertive communication skills with nurses in a rural setting. Published Master Dissertation. University of Wyoming. Available at: http://proquest.umi.com/pqdweb?

Seyedfatemi, N., Khoshnavaye, F. and Behbahani, N. (2009): Assertiveness skill and use of Ecsta

Among Iranian adolescents. Fundamentals of Mental Health.;10(4) pp: 265-72.

Shinde, M. and Durgawale, P. (2014): Nursing Audit of Health Workers Providing Health Services in Rural Area with Special Emphasis to Community Satisfaction in Satara District. International Journal of Science and Research (IJSR), 3(2), pp 94-104.

Unal, S. (2012): Evaluation the effect of selfawareness and communication techniques on nurses' assertiveness and self-esteem. Contemporary Nurse, 43(1),pp 90-98.

Yaffe, T. and Kark, R. (2011): Leading by example: the case of leader OCB. The Journal of applied psychology, 96(4), pp.806-826. 